\title{
Orienting a new generation of nurses: Expectations of the millennial new graduate
}

\author{
Elaine M. Riegel \\ Department of Nursing Education, St. Joseph Medical Center with Catholic Health Initiatives (CHI), Reading, USA \\ Email: elaineriegel@catholichealth.net
}

Received 30 July 2013; revised 1 September 2013; accepted 11 October 2013

Copyright (C) 2013 Elaine M. Riegel. This is an open access article distributed under the Creative Commons Attribution License, which permits unrestricted use, distribution, and reproduction in any medium, provided the original work is properly cited.

\begin{abstract}
Generational diversity provides a unique quandary for nursing leaders and educators to enlist, orient, and retain nurses. Millennials are the largest cohort since the Baby Boomers and the age group from which the nursing profession will build its future workforce. This study examined the experiences of the new graduate nurse of the millennial generation as they navigate orientation in an acute care setting. Using a Web-based survey to conduct the study allowed nurses from across the country to participate while providing easy access to the study questions. Analysis of the data through qualitative content analysis demonstrated a dominate theme of seeking structure while expecting an individualized orientation. The survey also revealed the importance of the preceptor and manager in the perceived success of this generation's transition and a need to assimilate into the professional role of $\mathrm{RN}$. Recognizing that there is a need to promote a more individualized orientation with improved mentoring for novice nurses and their preceptors is evident and challenges nursing leaders and educators to rethink current practices to retain new nurses. Established roles within the hospital and individual nursing units are changing and traditional strategies for recruitment and retention no longer apply. A structured orientation can facilitate the transition from new graduate to professional nurse and assist in the retention of qualified nurses and ultimately safe patient care.
\end{abstract}

Keywords: New Graduate Nurses; Millennial Nurses; Orientation; Generational Diversity

\section{INTRODUCTION}

For the first time in 30 years, the rate of aging in the nursing workforce has slowed, largely due to the increase in employed nurses under the age of 30 and rising enrollments in schools of nursing [1]. The increase in younger nurses entering the labor force is owed to the increase in baccalaureate nursing programs (BSN), whose student population is younger when compared to other nursing education programs [1]. A higher interest in nursing and an increase in applications to nursing schools significantly increased as the Millennial generation entered college age [2]. Unfortunately, in 2008 nearly $40 \%$ of recent graduates planned to leave their current jobs within three years; this is a significant increase from the $27.1 \%$ pre-2001 graduates [1].

This change in the demographics of nursing will impact all aspects of recruitment and retention as graduate nurses have become a considerable part of acute care hospitals strategy to fill workplace shortages [3]. A high turnover and an influx of new graduate nurses into the hospital setting leads to a higher proportion of inexperienced nurses, which may not only be traumatic for the new professional nurses, but also may impact patient safety [4].

Orientation is the introduction into the world of nursing and has the potential to influence not only the novice's nurse's practice but patient outcomes. The transition of gradate nurse from student to professional has been recognized as a time of stress, role adjustment, interpersonal conflict, and reality shock [4-7]. Although the discussion of practice readiness is not new, there is evidence to suggest that a new graduate's transition in the current healthcare environment is unique [6]. Increased acuity of hospital patients, reduced length of stay, nursing shortages, and demands for technology have placed increased stress on leaders and educators to move new graduate nurses into practice more rapidly [6]. Also, there is a trend to place novice nurses directly into highly specialized areas once reserved for the expert nurse [5].

In addition, hospital settings often have a bureaucratic structure with different generations of nurses following hierarchical lines. Younger nurses reported to people of 
the next generation with the oldest generation serving in the highest managerial positions. With the advent of total quality management and continuous quality improvement, a more team based approach has been adopted [8]. Shared governance has led to a flattening of this traditional hierarchy and facilitated decision making across the generations [8]. The information age has also altered the dependence of younger nurses on tenured staff for expert information.

The Millennials, also referred to as Generation Y or Net, are 88 million strong, and will comprise the majority of the workforce within the next two decades [9]. Although there have been many studies investigating new graduate transition into practice [5,6,10-14] only a few address this generation's distinctive characteristics $[7,15,16]$. This study examined the experience of the Millennial generation as they engage in the social context of their orientation process. The goal of the study was to inspire managers, educators, and coaches to rethink current practices that are designed for the masses.

\section{METHOD}

\subsection{Design}

A descriptive study was used to examine the experiences of Millennial new graduate nurses during orientation. The focus was to gain insight into the expectations of this generational cohort as they enter the health care workforce.

\subsection{Participants}

The nurses in this study were born between the years 1980-1989, and graduated from a nursing program within three years of the study. They were employed in acute care and had started or had recently finished their orientation process within the clinical setting. Of the seventeen participants, $47 \%(\mathrm{n}=8)$ worked in critical care, $35 \%(n=6)$ medical/surgical, $12 \%(n=2)$ in a pediatric setting and $6 \%(n=1)$ in ECU; 16 of the participants were female and 1 was male. Their nursing educational background included diploma $(n=4)$, associate degree $(n=1)$ and baccalaureate degree $(n=12)$.

In order to recruit participants, nurse educators within the Catholic Health Initiatives (CHI) health system and Kutztown University were provided, via email, information about the research proposal. The nurse educators were asked to seek out new graduate nurses via "word of mouth" who would meet the age criteria and provide an email address to contact the researcher if interested in participating in the survey. The new graduate nurses who contacted the researcher by email only needed to provide a return email address and were not asked to share any additional information. They were then sent a link via email that would be used to connect them to the Web-based survey. If they agreed to share their experiences, instructions were provided in the introduction of the survey explaining their consent and information to contact the researcher, the researcher's advisor and IRB representative with any questions. No potential risks were identified by participating in this research survey, and none of the nurses were compensated for their time. During completion of the survey, if they wished to discontinue their participation, they needed only click out of the screen and no information would be saved

\subsection{Instrumentation}

Using an online tool and email for communication assured confidentiality and permitted collection of data using technology familiar to this cohort. The study requested demographic data and proposed several open ended questions which required narrative responses. All questions used in the study were validated by a research advisor in the role of subject matter expert.

Questions included: "Describe your expectations of how nursing orientation would be conducted", "Describe ways in which your orientation met these expectations", "Describe ways in which your orientation did not meet these expectations", "What were your experiences of being a new graduate nurse in orientation", "Why did you select nursing as a profession?”, "How did your orientation impact your thoughts about nursing as a profession?" and "If you could give advice to another new graduate nurse entering their orientation, what would you tell them?”

\subsection{Data Collection}

The Web-based survey was available to research participants for three months and was closed when participant responses met saturation.

Changes brought by the use of computer technology have allowed the use of asynchronous communication such as email and online surveys to recruit and conduct research. The Internet has been used by other disciplines for both qualitative and quantitative data collection, as it allows for a wider geographical sampling, while decreasing the costs associated with data collection and time taken to collect the data $[17,18]$. Broader sample collection, easier recruitment of participants through the use of message boards, email lists and chat-rooms and speed of responses are several advantages of using the Internet for research [17-20].

\subsection{Data Analysis}

Colaizzi's [21] framework was used to guide the analysis of the participant's responses. Using this outline involved reading and rereading the responses, extracting signifi- 
cant statements and exposing meanings. Information was clustered into themes and then integrated into an exhaustive description of the phenomenon [22]. As this framework also requires returning to the participants to validate that the data represents their experiences [23], the participants were sent a follow-up email describing the themes extracted from the survey responses requesting any additional input.

\section{RESULTS}

The responses generated by the new graduate nurses reflected the theme of seeking structure including the expectation of an individualized orientation and open communication with preceptors and managers. A sub theme of role transition also surfaced as the new nurses expressed the need to assimilate into the unit's culture.

\subsection{Seeking Structure}

As the new graduate nurses described their experiences during orientation, the need for structure was a theme voiced by all of the participants. Within this topic of structure, the respondents revealed a need for consistency, organization and open communication. The new nurses entered their employment with a plan of how their orientation would flow. From review of policy and procedures, to actual task management in their unit, the nurses expected moving from simple to more complex tasks. One survey participant described the structure of their orientation as "the framework for me to build upon to become a more confident nurse”.

Building on a foundation of classes then clinical, new graduates anticipated their orientation to mimic the structure of their school environment. Several nurses described an expectation of orientation being similar to nursing school practicum with a mix of classes and on the unit training. One nurses commented that she "wanted more hands on learning, skills training or simulation”.

Not having exposure to the hospital environment other than in the clinical setting as a student, the new graduates did not anticipate the difficulties they would encounter practicing as an RN. Having a faculty nursing instructor allowed the student a consistent preceptor and provided structure during their clinical experiences. As a new RN, the nurses needed to find this structure from the ranks of their co-workers. A supportive and consistent preceptor increased the new nurse's confidence and aided in the new nurses abilities to function on the unit. Having goals set by their preceptor with constant feedback allowed the new nurse to feel prepared to practice on their own when orientation was complete.

Much of the disappointment listed by these novice nurses was related to inconsistent preceptors and lack of communication with their managers. There was a need to develop a routine and receive feedback on their performance. Many described feeling "overwhelmed” by the diverse routines of each new preceptor. Several described preceptors who "did not care" and were "pessimistic about their job" and others who would "not follow proper policy and procedure”. Also, having a preceptor function as the coach and charge nurse did not allow the preceptor to "devote herself to teaching", since she also had the role of managing an entire unit. This lack of role clarity and adjusting to different routines and personalities made orientation more confusing and complex. Inconsistent preceptors, to aid in their learning experience, were a frustration voiced by many of the new graduates.

Defining roles and responsibilities was another structure based theme expressed by the Millennial new graduates. They had difficulty knowing how to practice in this new role, and thus how to make critical thinking decisions. As students, they had the instructor to aid in any decision making, but as new graduates they were insecure in their judgment skills and expected a comprehensive classification of their roles and responsibilities. Communication was lacking, as the nurses were unsure how to make decisions in practice, and unclear where to find the information.

Within the theme of seeking structure the new nurses also expected an individualized orientation with a focus on their specific specialty. Orientees would be allowed to "work at their own pace" and "not feel rushed". Numerous responses from the survey mentioned specific time frames that nurses were given to complete their orientation instead of developing an orientation program based on their individual needs. Also, needing "time to sit down and discuss what was needed from our orientation with the preceptor and manager". Open communication between the manager, preceptor and new employee aided in individualizing the orientation for the new hire and minimized the expectation of orientation being set by a specific time frame. As many of the survey respondents were employed in an ICU setting, the anticipation of classes specific to their learning needs and more time to orient in a specialty area was expressed.

\subsection{Needing to Assimilate}

The transition from student to RN was another theme that emerged from the survey responses. Many of the respondents wrote about adjusting to personalities and finding their niche within the social ladder of the unit. The graduates felt overwhelmed and anxious when faced with the realities of their job and looked to their colleagues for support and mentorship. Both positive and negative experiences were voiced by the newcomers as they navigated through the territory of the incumbent nurses: 
"I learned a lot by asking my experienced co-workers questions. Was definitely a scary experience, especially not knowing who could be trusted. A couple older nurses were very mean and did not treat young, new nurses nicely.

Most of the nurses were supportive and willing to teach, but I felt as if some of the more 'senior' nurses would try to belittle the graduate nurses. It took a while to earn the respect of some nurses."

Participants also commented on the strong bonds they had formed with other new graduates and their preceptors. These relationships enabled the new graduate to connect to their unit and have a more successful transition into the culture. Several nurses expressed how the support they received from their coworkers impacted the success of transitioning from student to professional nurse. These relationships allowed them to form bonds, develop trust and adjust to the difficult realities of the job.

Value conflict and disenchantment with their new role as an RN were also expressed by the new graduates. Many entered nursing with an idealistic vision of the role and must compare this view to the actuality of the occupation. Graduates voiced their inner conflict with difficulties maintaining compassion and inability to control patient outcomes.

\section{DISCUSSION}

The need for structure, guidance and extensive orientation with formalized clinical coaching and feedback has been highly valued by this generation [24] and was a dominate theme expressed by these research participants. Millennials have been accustomed to nurturing and continuous feedback from their parents, sports team coaches, and teachers and have similar expectations in the workplace [16], "This generation is able to integrate large amounts of diverse sources of information and have little tolerance for inefficiency or ineffectiveness" [8]. LavoieTremblay, M., Paquet, M., Marchionni, C., \& Drevniok, U. [25] found that this generation of nurses sees coaching as a vital need; and coaching involves more than guidance during the first days or weeks, but a long term commitment. Nursing leadership must also be visible and transparent to this generation [6].

Preceptor matching is also a high priority to this generation, and there is evidence that preceptors play a significant role in the new graduate's experience [10]. Almada, P., Carafoli, K., Flattery, J., French, D., \& Mcnamara, M. [10] used Benner's model to guide a preceptor program in their institution which demonstrated improved retention of new graduate nurses. "According to Benner, new graduate nurses require the opportunity to practice and ask unlimited questions in a safe and supportive environment for an extended period of time"
[11] Lamp, K., Stratton, K., \& Welsh, J. [7] found that in addition to having consistent preceptors, it may be easier for the new graduate of this generation to learn from a preceptor with a similar communication style.

The desire for an individualized orientation was expressed frequently by the novice nurses in this research study. Growing up in a global economy, this generation expects multiple options and the ability to have customized alternatives [8]. They have attended public schools and universities where the Individualized Education Program is federally mandated to provide customized education plans for children with learning disabilities [26]. When they enter the workforce, the expectation of personalized orientation program to match their needs continues. In fact, new graduates of this generation with opportunities to have input into their own orientation have expressed an increased interest in their professional development [7]. Scott, E., Keeher, M., \& Swanson, M. [14] found that new graduates, in general, who experienced a longer orientation that met all of their needs, were more satisfied with their jobs.

The transition from student to nurse is experienced by all new graduate nurses and was a strong focus in many of the responses in this research study. It influenced both immediate and long-term outcomes in the process of becoming a nurse and orientation mark the most crucial part of the transition [12]. It is been documented by many studies that the first three months of employment as a new graduate nurse represents the most stressful time in a nurse's career [12]. Differences between work and school in terms of ideology and pragmatics are quickly realized, and Delaney [12] discovered that work presented different outcome objectives for the new nurses when compared to school. Duchsher [27] revealed feelings of disillusion with what the new graduate expected in their role as a professional nurse as compared to the actuality of practice. Prior to employment as a nurse, new graduates were found to be unprepared for and had limited awareness of what the profession of nursing entailed and had been shielded, as students, from the full breadth of the role [13]. Olson [16] documented in her research that the millennial novice nurse conveyed that the unfamiliarity with the acute care facility was a barrier to incorporate new knowledge, and as nursing students they did not have enough hours spent in an acute care facility. All these studies speak to the reality shock many new nurses encounter as they feel overwhelmed by their new role [11].

Many research studies connect conflict in the workplace with retention of nurses. During transition into practice, the achievement of some degree of attunement with colleagues was an important part of being able to function in the clinical setting [28]. The nurses in this study connected their ability to function safely on the clinical unit with the opportunity to seek assistance and 
ask questions. Zinsmeister \& Schafer [29] completed research on the transition into nurses first year of practice and noted that participants indicated that a supportive work environment contributed positively to their evolution into the professional role of a nurse. New nurses look to their colleagues for advice and questions about practice; Dyess and Sherman [6] reported many instances when new graduates received contradictory information with too many opinions and no confirmed answers. Millennials' especially appreciate a team based collaborative approach to work, since their educational experiences were based on interdependence and networking [30]. The new graduate of this generational cohort placed significant value on relationships and "finding their voice” [16].

The majority of the research participants in this study oriented in a specialty nursing unit and anticipated education related to patient management in their field. Dyes and Sherman [6] described new graduates in the high acuity specialty areas as needing not only extensive education related to technology and disease management but also emotional support related to intense patient situations that occur in these types of units.

\section{CONCLUSIONS}

New graduates currently comprise greater than $10 \%$ of acute care facilities nursing staff [16], and Millenials will be a great part of this statistic. The costs associated with training and coaching new graduates will be lost if retention rates remain low. The goal of this study was to understand the lived experiences of the millennial new graduate nurse, while appreciating the diverse differences in their expectations of training and education. "One size fits all" orientation programs will not provide the education needed by this generation and will contribute to turnover. Managers and educators need to rethink current practices and promote a team based environment while providing open communication and consistent feedback. Preceptor training and mentoring also needs to be a priority. Visibility of the manager and coach, and the influence of the unit's culture are crucial to the success of the new graduates first year [31].

Transition into practice, through residency programs, has been endorsed by the Institute of Medicine's Future of Nursing "Campaign for Action" [32], and appears to address the many of the issues confronting this new generation of nurses. Residency programs provide the structure and emotional support desired by this cohort while preparing new graduates to practice in a complex environment.

\section{REFERENCES}

[1] US Department of Health and Human Services (2010)
Health Resources and Services Administration. The Registered Nurse Population: Initial Findings from the 2008 National Sample Survey of Registered Nurses.

[2] Sherman, R. (2006) Leading a multigenerational nursing workforce: Issues, challenges and strategies. The Online Journal of Issues in Nursing, 11.

http://www.nursingworld.org/MainMenuCategories/ANA Marketplace/ANAPeriodicals/OJIN/TableofContents/Vol ume112006/No2May06/tpc30_216074.aspx

[3] Casey, K., Fink, R., Krugman, M. and Propst, J. (2004). The graduate nurse experience. Journal of Nursing Administration, 34, 303-311. http://dx.doi.org/10.1097/00005110-200406000-00010

[4] Park, M. and Jones, C. (2010) A retention strategy for newly graduated nurses. Journal for Nurses in Staff Development, 26, 142-149. http://dx.doi.org/10.1097/NND.0b013e31819aa130

[5] Baxter, P. (2010) Providing orientation programs to new graduate nurses: Points to consider. Journal for Nurses in Staff Development, 26, E12-E17. http://dx.doi.org/10.1097/NND.0b013e3181d80319

[6] Dyess, S. and Sherman, R. (2009) The first year of practice: New graduate nurse's transition and learning needs. The Journal of Continuing Education in Nursing, 40, 403410. http://dx.doi.org/10.3928/00220124-20090824-03

[7] Lamp, K., Stratton, K. and Welsh, J. (2011) Evaluating orientation preferences of the generation $\mathrm{Y}$ new graduate nurse. Journal for Nurses in Staff Development, 27, E6E9. http://dx.doi.org/10.1097/NND.0b013e3182236646

[8] Weston, M. (2006) Integrating generational perspectives in nursing. The Online Journal of Issues in Nursing, 11. http://www.nursingworld.org/MainMenuCategories/ANA Marketplace/ANAPeriodicals/OJIN/TableofContents/Vol ume112006/No2May06/tpc30 116073.html

[9] Christmas, K. (2008) Attracting and retaining millennialnurses.

http://www.nursingcenter.com/upload/static/1252649/Ber nardHodesWhitePaper.pdf

[10] Almada, P., Carafoli, K., Flattery, J., French, D. and Mcnamara, M. (2004) Improving the retention rate of newly graduated nurses. Journal for Nurses in Staff Development, 20, 268-273. http://dx.doi.org/10.1097/00124645-200411000-00006

[11] Cheeks, P. and Dunn, P. (2010) A new graduate program. Journal for Nurses in Staff Development, 26, 223-227. http://dx.doi.org/10.1097/NND.0b013e3181993b72

[12] Delaney, C. (2003) Walking a fine line: Graduatenurse's transition experiences during orientation. Journal of Nursing Education, 42, 437-443.

[13] Kelly, J. and Ahern, K. (2008) Preparing nurses forpractice: A phenomenological study of the new graduate in Australia. Journal of Clinical Nursing, 18, 910-918.

[14] Scott, E., Keeher, M. and Swanson, M. (2008) Newgraduate nurse transitioning: Necessary or nice? Applied Nursing Research, 21, 75-83. http://dx.doi.org/10.1016/j.apnr.2006.12.002

[15] Lavoie-Tremblay, M., Paquet, M., Marchionni, C. and Drevniok, U. (2011) Turnover intention among new nur- 
ses: A generational perspective. Journal for Nurses in Staff Development, 27, 39-45 http://dx.doi.org/10.1097/NND.0b013e31819945c1

[16] Olson, M. (2009) The "millennials": First year inpractice. Nursing Outlook, 57, 10-17. http://dx.doi.org/10.1016/j.outlook.2008.06.001

[17] Holmes, S. (2009) Methodological and ethical considerations in designing an internet study of quality of life: A discussion paper. International Journal of Nursing Studies, 46, 394-405.

http://dx.doi.org/10.1016/j.ijnurstu.2008.08.004

[18] Ogolsky, B., Niehuis, S. and Ridley, C. (2009) Usingonline methods and designs to conduct research on personal relationships. Marriage and Family Review, 45, 610-628. http://dx.doi.org/10.1080/01494920903224202

[19] Opdenakker, R. (2006) Advantages and disadvantages of four interview techniques in qualitative research. Forum: Qualitative Social Research, 7.

[20] Illingworth, N. (2001) The internet matters: Exploring the use of the internet as a research tool. Sociology Research Online, 6, 1-16. http://dx.doi.org/10.5153/sro.600

[21] Colaizzi, P. (1978) Psychological research as a phenomenologist views it. In: Valle R. and King, S., Eds., Existential-Phenomenological Alternatives for Psychology, Oxford University Press, New York.

[22] Shorter, M. and Stayt, L. (2010) Critical care nurses' experiences of grief in an adult intensive care unit. Journal of Advanced Nursing, 66, 159-167. http://dx.doi.org/10.1111/j.1365-2648.2009.05191.x

[23] Saunders, C. (2003) Application of Colaizzi's method: Interpretation of an auditable decision trail by a novice researcher. Contemporary Nurse, 14, 292-302. http://dx.doi.org/10.5172/conu.14.3.292

[24] Kramer, L. (2010) Generational diversity. Dimensions of Critical Care Nursing, 29, 125-128. http://dx.doi.org/10.1097/DCC.0b013e3181d24ba9

[25] Lavoie-Tremblay, M., Leclerc, E., Marchionni, C. and
Ulrika, D. (2010) The needs and expectations of generation Y nurses in the workplace. Journal for Nurses in Staff Development, 26, E2-E8. http://dx.doi.org/10.1097/NND.0b013e3181a68951

[26] US Department of Education (2000) Individualized education program. http://ed.gov/parents/needs/speced/iepguide/index.html

[27] Duchsher, J. (2001) Out in the real world: Newly graduated nurses in acute care speak out. Journal of Nursing Administration, 31, 426-439. http://dx.doi.org/10.1097/00005110-200109000-00009

[28] Malouf, N. and West, S. (2011) Fitting in: A pervasive new graduate nurse need. Nursing Education Today, 31, 488-493. http://dx.doi.org/10.1016/j.nedt.2010.10.002

[29] Zinsmeister, L. and Schafer, D. (2009). The exploration of the lived experience of the graduate nurse making the transition to registered nurse during the first year of practice. Journal for Nurses in Staff Development, 25, 28-34. http://dx.doi.org/10.1097/NND.0b013e318194b58c

[30] Kupperschmidt, B. (2006) Addressing multigenerational conflict: Mutual respect and care fronting as strategy. Online Journal of Issues in Nursing, 11, 1-15. http://www.nursingworld.org/MainMenuCategories/ANA Marketplace/ANAPeriodicals/OJIN/TableofContents/Vol ume112006/No2May06/tpc30_316075.html

[31] Fink, R., Krugman, M., Casey, K. and Goode, C. (2008) The graduate nurses experience: Qualitative residency program outcomes. The Journal of Nursing Administration, 38, 341-348. http://dx.doi.org/10.1097/01.NNA.0000323943.82016.48

[32] Institute of Medicine (2011) The future of nursing: Leading change, advancing health. National Academies Press, Washington DC. http://www.nap.edu/catalog/12956.html 